\title{
Overlooked Benefits of Nutrient Reductions in the Mississippi River Basin $₫$
}

\author{
Bryan Parthum National Center for Environmental Economics, U.S. Environmental Protection Agency, \\ Washington D.C.; parthum.bryan@epa.gov \\ Amy W. Ando Professor, Department of Agricultural and Consumer Economics, University of Illinois \\ Urbana-Champaign; and university fellow, Resources for the Future, Washington, DC; \\ amyando@illinois.edu
}

\begin{abstract}
Improvements in local surface water quality in the Mississippi River Basin (MRB) can contribute to the regional environmental goals of reducing hypoxia in the Gulf of Mexico. To inform estimates of the benefits of water quality policy, we use a choice experiment survey in a typical subwatershed of the MRB to estimate willingness to pay for local environmental improvements and helping to reduce hypoxia far downstream. We find that residents place large values on reduced local algal blooms, improved local fish populations and diversity, and meeting local commitments to help with the regional environmental problem. (JEL Q52, Q53)
\end{abstract}

\section{Introduction}

Nutrient pollution and hydrological disruption cause water quality impairments throughout the Mississippi River Basin (MRB) and serious problems with widespread oxygen depletion called hypoxia in the Gulf of Mexico (U.S. Environmental Protection Agency 2008). The U.S. Environmental Protection Agency's 2008 Gulf Hypoxia Action Plan (GHP) tasked the 12 upstream states with the responsibility of reducing their transmission of nutrients such as nitrate-nitrogen and phosphorus by $45 \%$ by the year 2040 . In an approach similar to the other states in the MRB, agencies in Illinois created the Illinois Nutrient Loss Reduction Strategy (INLRS) to coordinate efforts in that state to meet the nutrient reduction targets. The INLRS promotes voluntary efforts by farmers to reduce nutrient

Land Economics • November 2020 • 96 (4): 589-607 ISSN 0023-7639; E-ISSN 1543-8325

(C) 2020 by the Board of Regents of the University of Wisconsin System runoff into local waters, but a major policy change such as state subsidies will be needed to accomplish the 2040 goals (Coppess 2016). State agencies and lawmakers are, therefore, interested in how much their own residents would support efforts to meet the INLRS targets. How much value do residents of the MRB gain from changes to water quality in their local watersheds, and to what extent do people in a state like Illinois value their local watershed's contribution to nonlocal improvements such as reducing the scale of the hypoxic dead zone in the Gulf of Mexico?

Integrated assessment of surface water quality policies and management actions can benefit from information about the total values of changes in water quality and the distribution of those values among different groups of people. A host of previous studies have shed light on the values people place on some dimensions of pollution reduction within the United States. That work is surveyed by Bergstrom and Loomis (2017); meta-analyses of those studies have informed benefit transfer efforts to estimate aggregate benefits of water quality changes at the national level (Johnston, Besedin, and Stapler 2017; Moeltner 2019). There is also a long line of research exploring the differences between use and nonuse values from local and nonlocal improvements in surface water quality in the United States (Greenley, Walsh, and Young 1981; Lant and Roberts 1990; Carson and Mitchell 1993; Johnston, Besedin, and Wardwell 2003; van Houtven, Powers, and Pattanayak 2007), and recent work has emphasized the need to examine these relationships when considering the benefits from policies that reduce hypoxia in the Gulf of Mexico (Babcock and Kling 2015; Keiser, Kling, and Shapiro 2019). This paper advances research on water qual-

Appendix materials are freely available at http://le.uwpress.org and via the links in the electronic version of this article. 
ity valuation and integrated assessment with a choice experiment survey that estimates three conventional benefits of water quality improvements (improvements in local fish populations, fish diversity, and reductions in local algal blooms) and previously overlooked benefits (local contributions to reaching a regional nutrient reduction target) that arise from policies targeting hypoxia in the Gulf of Mexico. ${ }^{1}$ We then illustrate how to use those values in a spatially disaggregated integrated assessment of a land use management plan and explore two dimensions of value heterogeneity.

The bottom line of a benefit-cost analysis often aggregates benefits of environmental improvements to all people affected by the policy. However, many policy makers and interest groups are particularly concerned about the net impact of agricultural-environmental policies on rural residents (Gibbs 2016; Farber 2018), although evidence regarding preference heterogeneity between rural and urban areas is mixed. Some research shows that urban residents give more support for environmental policies than people in rural areas of the United States (Salka 2001), and other research finds little difference between rural and urban residents in their interests for environmental quality (Arcury and Christianson 1993; Mobley 2016). Racevski and Lupi (2006) find rural residents in Michigan are less likely to support forest management efforts involving conservation, but conclude this is likely because those rural communities rely on forests products for production or exports. Melstrom et al. (2015) find that urban rivers and streams are less valued than rural rivers for recreational fishing, but do not estimate the differences in preferences between rural and urban recreationists themselves. We make a contribution to this discussion in the context of surface water quality by testing whether the values that people place on water quality improvements vary between people in rural areas and people in urban areas of the same watershed, located in the heart of the MRB.

\footnotetext{
${ }^{1}$ Phaneuf (2002) estimates use values within a watershed for achieving total maximum daily load targets (nutrient reductions). We extend this analysis to estimate the local (within the watershed) benefits of contributing to regional, downstream (outside the watershed) nutrient reduction targets.
}

Previous research in stated preference valuation shows that spatial dimensions matter in other important ways. First, willingness to pay (WTP) for an environmental improvement can vary widely across space (Johnston and Duke 2007; Brouwer, Martin-Ortega, and Berbel 2010). In particular, people often have higher WTP when they are closer to the improvement (Sutherland and Walsh 1985; Hanley, Schläpfer, and Spurgeon 2003; Czajkowski, Budziński, et al. 2017; Glenk et al. 2019). Second, researchers have found that when estimating WTP for an environmental change that has a specific location within the landscape, the quality of responses from stated preference surveys depends on how clearly the survey describes the location of the change relative to the respondent (Schaafsma and Brouwer 2013; Johnston, Holland, and Yao 2016). Our survey shows respondents exactly where they live relative to the proposed improvements. We also vary distance from the improvement experimentally across alternatives to identify how WTP varies with exogenously determined distance from the environmental good.

We find that people place positive and significant values on local water quality improvements and on helping to achieve basinwide success in reducing hypoxia in the Gulf of Mexico. We do not find evidence of joint differences in preferences between rural and urban residents in the same watershed. We do, however, find that rural residents and people who are familiar with nutrient pollution problems place more value on moving away from the status quo conditions in the watershed regardless of the improvements a program produces. Finally, we demonstrate how these estimates can be used in spatially disaggregated integrated assessments, where benefit totals and distributions depend on spatial details of the improvements and the population that stands to gain.

\section{Application}

Freshwater systems throughout the U.S. Midwest have been severely altered due to decades of intensive agriculture production (Manifold 1998; Alexander et al. 2008). Tributaries lo- 
cated within the upper MRB carry excess nutrients, byproducts of intensive agriculture production, to the Mississippi River, where they are eventually released into the northern Gulf of Mexico. An overabundance of these nutrients contributes to the large seasonal hypoxic dead zone off the cost of Louisiana and Texas (Diaz and Rosenberg 2008; Rabalais et al. 2010; Rabotyagov et al. 2014).

This paper presents survey results from people in the Upper Sangamon River Watershed (USRW) in central Illinois (Figure 1). This watershed is listed as a priority watershed due to its high levels of nitrate-nitrogen and phosphorus transmission within the MRB (U.S. Environmental Protection Agency 2008, 2013). The population in the study area is diverse and includes large swaths of rural landscape with several urban clusters. The characteristics of the USRW are representative of many watersheds in the MRB, providing an excellent setting for examining value differentials and policy-induced distributional effects across rural and urban populations in the MRB.

State agencies, university extension personnel, researchers at the University of Illinois, and people from groups like the Illinois Farm Bureau have been active in communicating about the INLRS in the state, explaining the goals of the INLRS and how agricultural practices such as cover crops, reduced tillage, and riparian buffers can reduce nutrient loadings. It has been shown that stated preferences for environmental goods, and the underlying latent consequentiality of a survey, are more reliable when respondents have prior knowledge of the issues and policies that are being discussed (Whitehead et al. 1995; LaRiviere et al. 2014; Czajkowski, Hanley, and LaRiviere 2015; Czajkowski, Vossler, et al. 2017; Needham and Hanley 2020) — as is the case in our survey.

\section{Choice Experiment Methodology}

Choice experiment surveys are widely used to elicit preference for nonmarket environmental amenities such as water quality in rivers
Figure 1

Study Area in Upper Sangamon River Basin, Central Illinois: The Four Sections of River (A, B, C, D) Are Highlighted and Included as Attributes on the Choice Card

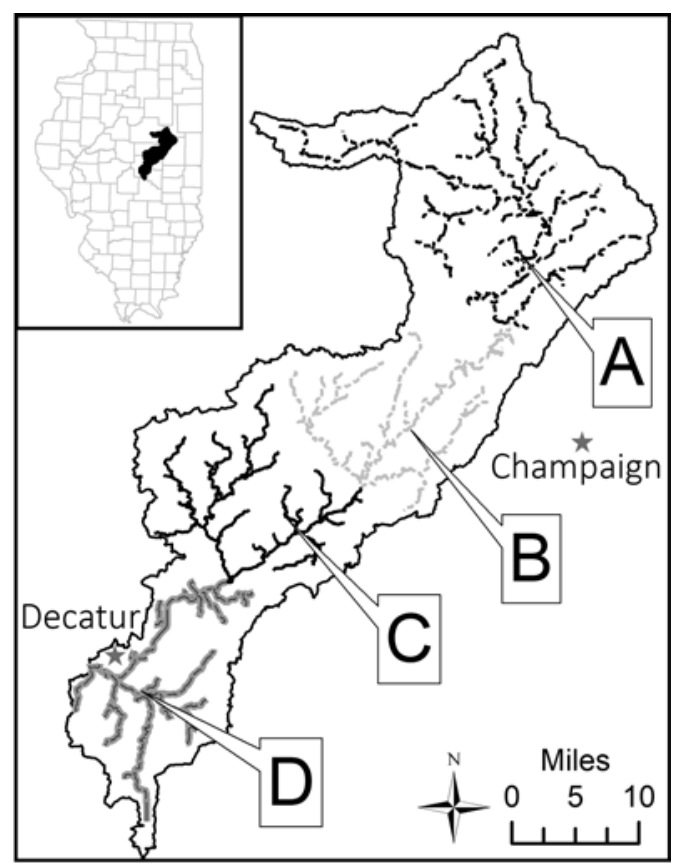

and streams. Using this platform allows us to model preferences in the random utility maximization (RUM) framework (McFadden 1973). Preferences are characterized by estimating the probability a respondent chooses a scenario from a set of alternatives with varying levels of environmental quality (Hanley, Wright, and Adamowicz 1998).

Each respondent began the survey by reading a consent form describing the purpose and nature of the survey and gave consent to continue with the survey. Respondents were then presented a background section that provided basic information about nutrient pollution problems in the MRB and the general nature of the improvements to be evaluated in the survey. After the respondent read the background section, they answered six choice questions and supplemental questions about personal characteristics.

We held a series of focus groups throughout the watershed with attendees from the general population. They were asked to take 
Table 1

Survey Attributes and Levels

\begin{tabular}{|c|c|c|}
\hline Attribute & Levelsa & Description \\
\hline Fish species & (1), $2,3,5$ & Number of different recreational game fish species per 100 yards of river \\
\hline Fish population & $(15), 30,45,150$ & Number of all fish per 100 yards of river \\
\hline Algal blooms $(\%)$ & $(0), 25,50,75$ & Percent reduction in the frequency of local algal blooms \\
\hline Nutrient target $(\%)$ & $(0), 50,75,100$ & $\begin{array}{l}\text { Likelihood that nutrient run-off from this watershed is reduced by the target of } \\
\text { " } 45 \% \text { by } 2040 "\end{array}$ \\
\hline Location & $\mathrm{A}, \mathrm{B}, \mathrm{C}, \mathrm{D}$ & The section of river where the improvements will be received \\
\hline Distance & (Varies) & $\begin{array}{l}\text { The distance in miles from the respondent to the nearest point on the location } \\
\text { attribute; this depends on where the respondent lives and which location is } \\
\text { represented in the scenario }\end{array}$ \\
\hline Annual cost & $(0), 5,15,30,60$ & Payment vehicle: annual county fee (e.g., property tax) \\
\hline
\end{tabular}

the survey and participate in a 30-minute follow-up discussion. In response to focus group feedback, we revised the survey to incorporate their suggestions regarding ambiguities in management mechanisms and wording of the attribute changes. We deployed the survey in a pretest with 79 completed surveys (474 observations) and adjusted the levels of the cost attribute so that all levels were chosen with some frequency. Finally, we distributed the survey to a randomly selected group of respondents living within the watershed.

\section{Consent and Background}

Several features of the survey were designed to increase respondent belief in consequentiality and prevent concern about agricultural regulation that might trigger protest responses. The consent form explained that "information from this survey will help policy makers, economists, and watershed managers choose how and how much to improve water quality in your area." The University of Illinois is regionally known to be connected to state policy makers and agricultural decision-makers, supporting the claim that the survey will be consequential.

The background section of the survey tells respondents about the regional goal for nutrient loss reduction to reduce the size of the hypoxic zone and the nutrient pollution reduction target for the Upper Sangamon River watershed's contribution to that goal. This section explains that the proposed environmental changes would come from changes in local agriculture, such as expanded cover crops, reduced tillage, and riparian buffers; these voluntary and subsidized practices can reduce sediment and nutrient runoff from the surrounding area and are currently well accepted and widely used by farmers throughout the region. The survey scenarios with water quality improvements from such changes in agricultural practices are within the range of future actions actually being discussed in the state, and thus not entirely hypothetical. In the survey background we explicitly state that an environmental change "will NOT result in a change in agricultural acreage or profits," to further prevent concern about the profitability of local agriculture from being confounded with the value people would gain from environmental improvements. ${ }^{2}$

\section{Choice Questions}

A choice question is posed in a "card" that shows a set of scenarios and asks respondents to choose the scenario they like most. In our survey, each scenario in a choice card has seven experimentally varied attributes. Four of those attributes relate to biophysical characteristics of water quality, two capture spatial heterogeneity, and one is the payment necessary to implement the proposed improvements. Table 1 summarizes each attribute, specifying the status quo and improved levels of each attribute. Our choice experiment survey is tightly coupled to biophysical models

\footnotetext{
${ }^{2}$ The full survey text can be found in Appendix A.
} 
of watershed improvements; the levels of the biophysical attributes were informed by the work of hydrological and ecological modelers in the USRW. Botero-Acosta, Chu, and Huang (2019) model predicted changes in nutrient levels throughout the USRW resulting from hypothetical changes in local agricultural practices. Andres, Chien, and Knouft (2019) use these predicted changes in nutrient levels, climate, and data from 110 monitoring sites across the USRW to model changes in aquatic biodiversity.

Three of the four biophysical attributes related to water quality are local, and one is nonlocal. Number of fish species and population of fish (two independent attributes) are local quantitative measures summarizing the current average number of distinct species of fish (diversity) and populations of individual fish per 100 linear yards of river (density). Dissanayake and Ando (2014) find that Illinois residents have positive value for both species diversity and faunal density in grassland birds; we test whether people value two such attributes of fish in inland streams. Improvements in local surface water quality are also captured as percent reductions in the frequency of algal blooms in the local watershed including streams and ponds; that reduction ranges from $0 \%$ to $75 \%$. The fourth nutrient-pollution attribute describes the likelihood that this watershed succeeds in meeting its targets for reductions in the level of nutrient transmission to the Gulf of Mexico and ranges from $0 \%$ (definitely will not succeed) to $100 \%$ (certain to succeed).

Local water quality-related changes from a nutrient-loss reduction strategy are not uniform throughout a watershed, but rather depend on local details such as depth, flow rate, and shade. We partition the watershed into four equally sized sections. Each scenario specifies the section of the watershed in which water quality attributes improved. The location attribute varies as part of the experiment design; as a result, distance (measured as the distance from each respondent to the improved section of the watershed) also varies experimentally.

The final attribute in each scenario is the household payment necessary to achieve the proposed improvements, cost. We use an increase in annual county fees as the payment
Figure 2

Frequency of Chosen Attribute Levels
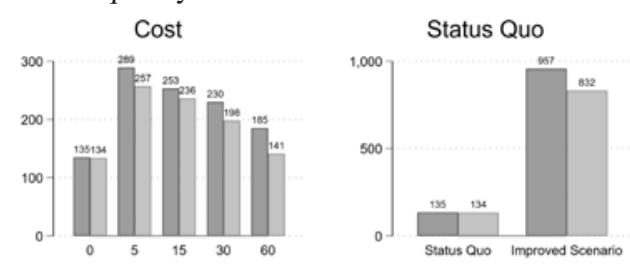

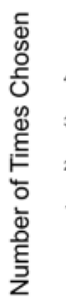
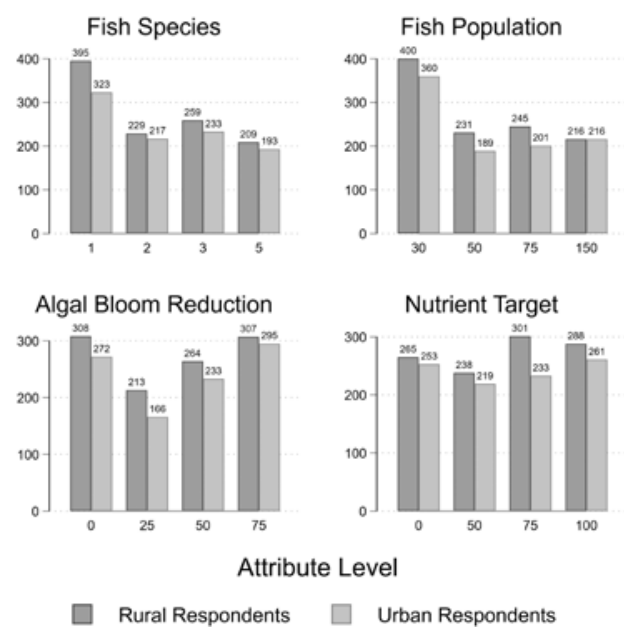

vehicle, verifying with focus groups that this is a salient and credibly binding mechanism for payment. The survey states that the fee will be passed on to renters through an annual increase in rent charged by the landlord. Figure 2 shows that all attribute levels were chosen with some frequency by respondents.

We designed the survey to increase estimation efficiency while maintaining reliability in WTP estimates. In theory, choice experiments are demand revealing only if they are incentive compatible (Carson and Groves 2007), and while a dichotomous choice design (one status quo and one alternative) is often argued to be incentive compatible, trichotomous choice (one status quo and two alternatives) is not. However, trichotomous choice increases the amount of information recovered from each survey response, and some research shows that values are similar between the two mechanisms (Collins and Vossler 2009). Thus, we include two alternatives along with the status quo on every choice card.

In stated preference research, hypothetical bias can influence estimates of WTP 
(Cummings, Harrison, and Rutström 1995; Cummings and Taylor 1999). We include a modified cheap talk script in the information section of the survey and an opt-out reminder on each choice card (Ladenburg and Olsen 2014) to mitigate such bias. ${ }^{3}$ After each choice card, we also include certainty questions asking how sure the respondents were of the selection they just made (Ready, Champ, and Lawton 2010; Penn and $\mathrm{Hu} 2020){ }^{4}$

\section{Experimental Design}

We develop an optimal orthogonal choice matrix resulting in a D-efficient experiment design (Adamowicz, Louviere, and Swait 1998; Hensher, Rose, and Greene 2005; Street and Burgess 2007; Ferrini and Scarpa 2007). As recommended by Ferrini and Scarpa (2007), the design is optimized for main effects with zero priors $(\beta=0)$ to produce a reliable design when the true underlying data generating process is unknown and prior information on parameter values is not available. We produce 18 unique choice cards from the full factorial design, divided into three blocks of six choice cards. Respondents are randomly assigned one of the three blocks of six choice cards. The number of cards and alternatives are chosen to limit cognitive burden for the respondents while maintaining statistical power to estimate WTP (Swait and Adamowicz 2001; Caussade et al. 2005).

After we created an initial design, we imposed two additional conditions for the final design, and reran the design if the conditions

\footnotetext{
${ }^{3}$ The cheap talk script included in the information section reads: "Experience from previous similar surveys is that people often say they would be willing to pay more money for something than they actually would. For example, in one study, $80 \%$ of people said they would buy a product, but when a store actually stocked the product, only $43 \%$ of people actually bought the new product. It is important that you make each of your upcoming selections like you would if you were actually facing these exact choices in reality. Note that paying for environmental improvement means you would have less money available for other purchases."

${ }^{4}$ The question asks: "How confident are you in your answer?" With the range: " 0 - not at all confident"; " 1 - somewhat confident"; and "2 - very confident." We use these responses to recode uncertain responses to the status quo alternative. Results and discussion of these regressions are available in Appendix C.
}

were not met. The first condition is a no-freelunch restriction (improvement in any attribute will come at a nonzero cost) and a welfare improving restriction (no improvement across all attributes cannot come at a cost). The second condition checks if any of the 18 resulting choice cards has an alternative that was strictly dominated by another alternative on the same card (e.g., a higher level of improvements at a lower cost). After seven iterations of the two-step procedure-each iteration consisting of many design iterations in the first step-all conditions were met. ${ }^{5}$

With the exception of location and distance, we allow the status quo level of each attribute to be randomly included in the improved (nonstatus quo) scenarios. We include an alternative specific constant (ASC) to represent the status quo alternative on the choice card. The ASC captures preferences that the respondent may have for maintaining the status quo that are unobservable and not otherwise contained in our experimental design.

\section{Individualized Maps and Choice Card Generation}

Following recommendations highlighted by Johnston, Holland, and Yao (2016), each alternative on a choice card includes an individually geocoded map highlighting the section of river that would experience the improvements and a marker locating the respondent within the watershed relative to the proposed improvements. Each map was created for the individual respondent and geocoded using ArcPy integration in ArcGIS. Eight towns and city centers distributed throughout the watershed are geolocated to provide a "you are here" marker in each map. The total number of combinations of choice cards, alternatives, and geolocations resulted in 432 different individualized maps and 432 different levels for the distance attribute listed as an attribute on the choice card.

In order to accommodate the individualization of alternatives and choice cards, we cre-

\footnotetext{
${ }^{5}$ We generated the design using the dcreate package implemented in Stata (Hole 2015). We created a wrapper for the dcreate package that allows us to impose the additional restrictions on the design.
} 
ated images of the choice cards by integrating the mail-merge capabilities of Microsoft Publisher, referencing an underlying matrix of all individualized combinations of the experiment design. The resulting pages of the document were then extracted by the survey protocol using Python to create an image for each page representing a choice card in the experiment. The 432 choice cards images were then stored online using Amazon Web Services and referenced in real time while the respondent was taking the survey.

\section{Other Survey Questions}

We designed the survey instrument to test for potential preference heterogeneity between residents who identify as rural, and those who identify as urban. That characteristic was examined in two dimensions: (1) geographical affiliation and (2) cultural affiliation. The first, geographical affiliation, is simply determined using the U.S. Census Bureau's classification of rural - a census block group area with less than 1,000 residents per square mile (Ratcliffe et al. 2016). Respondents who fit this designation are classified as living in a geographically rural area, all others are classified as living in an urban area. The second, cultural affiliation, is determined by the respondent's stated affiliation in the postsurvey questionnaire. The question was phrased as: "Do you consider where you live to be rural?" Respondents in our sample overwhelmingly responded with a cultural affiliation that aligned with their geographical affiliation. Our design allows us to test the hypothesis that preferences for surface water quality are the same between those who live in a geographically and culturally rural area and those who live in a geographically and culturally urban area.

In order to understand other characteristics of our survey sample, we ask two sets of personal questions. Three questions come before the choice questions and ask about the frequency with which people had seen algal blooms, how often respondents visited the river to go fishing, and how often they recreated nearby the river. A section after the choice questions contains common demographic and socioeconomic questions.

\section{Survey Administration}

The survey was administered online using a Qualtrics panel of respondents through their survey interface, paired with additional JavaScript and HTML to incorporate the individualized choice cards. ${ }^{6}$ Respondents were recruited from the 42 zip codes contained within the watershed. Once respondents received an invitation to take the survey, they would arrive at the online interface where they were asked to enter their zip code. If the zip code was not one of the 42 qualifying, they were screened and exited from the survey. The next step individualizing the choice experiment was to ask respondents which of the eight locations (towns or city centers) they lived closest to. Their response would then cue the system to load a randomly ordered set of choice cards. Our final sample has complete responses from 343 individuals.

\section{Econometric Framework}

Following choice experiment methodology (Hanley, Wright, and Adamowicz 1998; Johnston et al. 2017), we assume that a respondent derives utility based on the observable characteristics contained within the choice card, and some characteristics unobservable to the researcher. Specifically, $U$ is the utility respondent $i$ derives by choosing alternative $j$ on choice card $t$ :

$U_{i j t}=-\alpha_{i} p_{j t}+\beta_{i}^{\prime} x_{j t}+e_{i j t}$.

where $\mathbf{x}$ is a vector of attributes, $p$ is the price $(\cos t)$ of the scenario, and $e$ is the stochastic component capturing unobservable characteristics influencing the respondent's choice and is an independent and identically distributed (IID) extreme value. Included in $\mathbf{x}$ is an ASC that is equal to 1 for the status quo alternative in each choice set, and 0 otherwise. $\boldsymbol{\beta}$ is the vector of preference coefficients, and $\alpha$ is the coefficient on cost. Both $\beta$ and $\alpha$ are indexed to be respondent specific when estimated us-

\footnotetext{
${ }^{6}$ The first wave of survey responses was collected from January 2019 through February 2019. A second collection period was administered January 2020 through February 2020.
} 
ing a random parameter logit model (Train 1998).

The variance of the error term also varies with each respondent such that: $\operatorname{Var}\left(e_{i j t}\right)=k_{i}^{2}\left(\pi^{2} / 6\right)$, where $k_{i}$ is the scale parameter for respondent $i$. Variation in the error term can be attributable to scale heterogeneity or other forms of correlation between the model attributes, particularly so in panel (repeated choice occasion) settings such as ours (Swait and Louviere 1993; Train and Weeks 2005; Hess and Train 2017). Dividing the preference parameters by the scale parameter where $\lambda_{i}=\left(\alpha_{i} / k_{i}\right)$ and $c_{i}=\left(\beta_{i} / k_{i}\right)$ results in a specification that has the same variance for all respondents:

$U_{i j t}=-\lambda_{i} p_{j t}+c_{i}^{\prime} x_{j t}+\epsilon_{i j t}$.

where $\epsilon_{i j t}$ is an IID type-one extreme value, now with a constant variance: $\pi^{2} / 6$. With $k_{i}$ in the denominator of each coefficient, allowing the coefficients to be independent (not correlated) would constrain the scale parameter to be constant for the sample while allowing the preference parameters to vary, or vice versa (Louviere et al. 2002). Equation [2] is the model in preference space (Train and Weeks 2005). To avoid the postestimation difficulties in deriving empirical distributions of WTP (Train 1998; Daly, Hess, and Train 2012; Carson and Czajkowski 2019), we choose to estimate our model in willingness to pay space (WTP-space) directly (Train and Weeks 2005; Scarpa, Thiene, and Train 2008). ${ }^{7}$ This is a standard reparameterization of equation [2] such that $w t p_{i}=c_{i} / \lambda_{i}$; utility is then represented by

$U_{i j t}=-\lambda_{i} p_{j t}+\left(\lambda_{i} w t p_{i}\right)^{\prime} x_{j t}+\epsilon_{i j t}$.

Equation [3] is the specification in WTP-space (Train and Weeks 2005). We specify the wtp parameters to be distributed normally, and the coefficient on cost, $\lambda_{i}$, is distributed log-normally as outlined by Train and Weeks (2005). We specify the distributions of the random parameters to be fully correlated, estimating

\footnotetext{
${ }^{7}$ We also estimate our models using conventional preference-space specifications. These specifications, along with their discussion, can be found in Appendix C.
}

a full covariance matrix and corresponding correlation coefficients for the random parameters in the model. We follow Thiene and Scarpa (2009) and estimate the model using maximum simulated likelihood. Halton draws were used in the maximum-likelihood simulation. The first $N$ prime numbers were used to generate the draws, where $N$ is equal to the number of random parameters in our model. ${ }^{8}$

To develop estimates of total WTP and its distribution throughout the watershed for hypothetical improvements in water quality, we allow for location-specific and individual-specific heterogeneity in estimates of marginal WTP (MWTP) by recovering the conditional individual specific means of the parameters in equation [3] (Greene, Hensher, and Rose 2005; Meyerhoff, Boeri, and Hartje 2014). This is discussed in more detail in Section 6, where we discuss the integrated assessment model exercise.

\section{Results}

Our sample is evenly divided between people in rural (53\%) and urban (47\%) areas, and $56 \%$ of the sample's respondents own homes instead of renting. ${ }^{9}$ Respondents are predominantly white $(78 \%)$ and female $(68 \%)$; the former is consistent with the actual demographics of the area. Our sample has broad representation of age, income, and education categories, and the distributions in our sample are similar to those of the U.S. Census demographics for this area. This is an area with little in-migration; half the people in our sample have lived in the area for more than 30 years, and only $10 \%$ have lived there for 10 years or fewer. The two subsamples are mostly similar, except that urban respondents are more likely to hold a graduate degree and less likely to participate in recreational fishing and hiking. ${ }^{10}$

\footnotetext{
${ }^{8}$ All specifications and analyses are modeled using the gmnl package in R (Sarrias and Daziano 2017).

${ }^{9} \mathrm{~A}$ full summary of responses to demographic questions and comparison to the American Community Survey can be found in Appendix B.

${ }^{10}$ The results of testing for observable differences between rural and urban respondents can be found in Appendix B.
} 


\section{Figure 3}

Responses to Questions about How Familiar Respondents Are with Water Quality Issues in the Watershed and How Frequently They Experience Algal Blooms in Surface Waters in the Watershed

Frequency seeing algal blooms

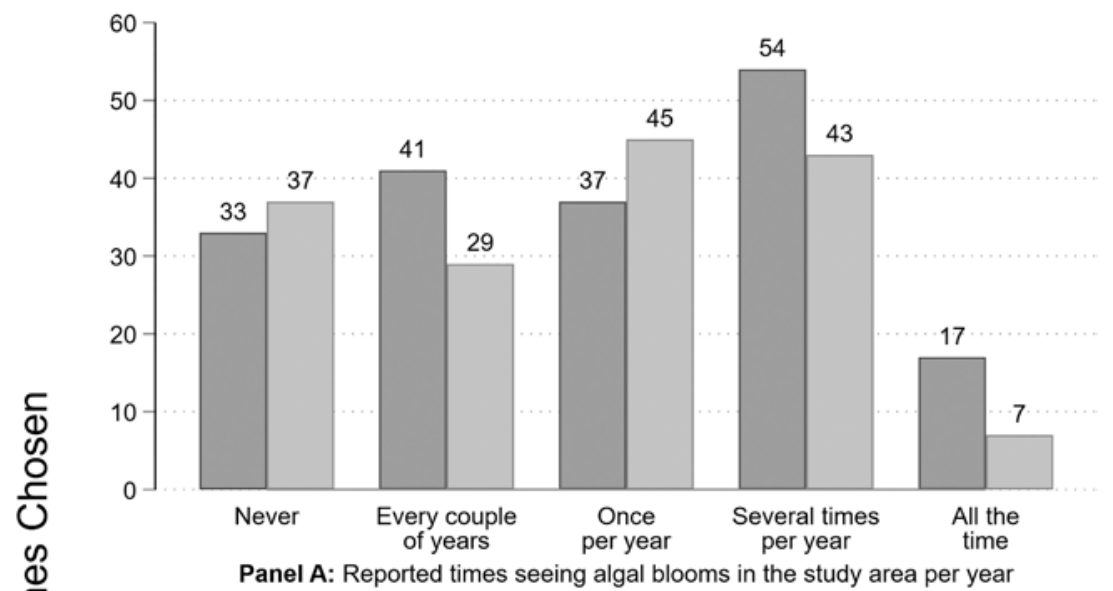

\section{Familiarity with water quality issues}

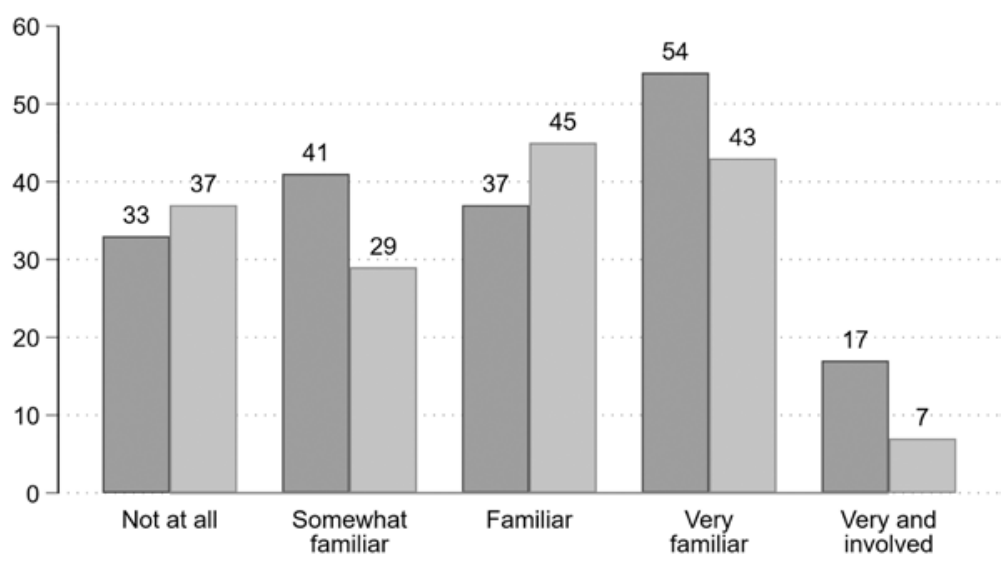

Panel B: Reported familiarity with the water quality issues discussed

\section{Rural Respondents}

Figure 3 shows the distributions of answers to qualitative questions about familiarity with local algal blooms and water quality concerns described in the survey. Nearly $80 \%$ of the sample reported having at least some familiarity with the water quality issues discussed in the survey, and about the same number of respondents reported experience with algal blooms in the rivers or connected bodies of water. Fewer than $20 \%$ of respondents reported having fished in the USRW at all. However, nearly $50 \%$ reported having visited the river or walked trails near the river. ${ }^{11}$

Table 2 presents the main regression results, estimating equation [3] (WTP-space)

\footnotetext{
${ }^{11} \mathrm{~A}$ full summary of responses to visitation questions can be found in Appendix D.
} 
Table 2

Marginal Willingness to Pay (MWTP) to Reduce Nutrient Transmission to the Gulf of Mexico

(1)

Full Sample

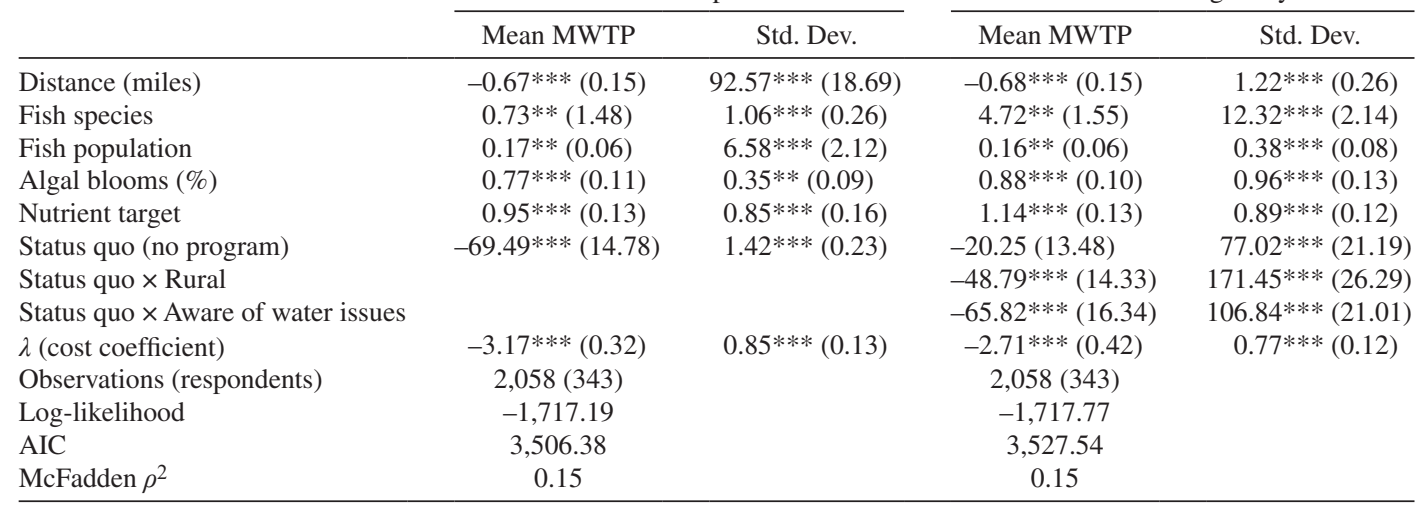

Note: Standard errors in parentheses. Column 1 provides the results of the WTP-space model for the pooled (full) sample. Column 2 introduces an interaction between the status quo dummy and respondent characteristics. Correlation matrices of the random parameters can be found in Appendix C. ASC, alternative specific constant.

$* p<0.05 ; * * p<0.01$; *** $p<0.001$.

for the full sample. The regression in column 1 includes just the core model parameters. The regression in column 2 introduces an interaction term between the status quo dummy (ASC) and several respondent characteristics.

All mean WTP coefficients in column 1 are statistically significant at the $1 \%$ level. The coefficient on the status quo (no program) option is large and negative and suggests respondents strongly prefer having a water-quality improvement program than not. The coefficient on distance is also negative-people prefer a program focused on the river close to where they live. The coefficients on fish species and fish population are positive; people would be willing to pay nearly $\$ 5$ per year to have an additional species of game fish in the river, and they separately place a positive value on the total number of individual fish in the river. The coefficients on algal blooms and nutrient target are positive. People would gain utility from reducing the frequency of these local problems in their watershed, with an average annual MWTP of $\$ 0.77$ for a $1 \%$ reduction in the frequency of algal blooms. Respondents also place a large value on nutrient target, with an average annual MWTP of $\$ 0.95$ for a 1 percentage point increase in the likelihood of achieving the watershed's nutrient loss target.

The large MWTP to move away from the status quo suggests that respondents have strong preferences for having a new program instead of the status quo regardless of the variable attributes in our choice scenarios. Column 2 explores two factors contributing to these preferences. Respondents who live in more rural areas of the watershed and respondents who are familiar with surface water issues in the area are willing to pay significantly more for moving away from the status quo. Rural residents are estimated to value this move from status quo \$49 more than urban residents. Those who reported being familiar, very familiar, or very familiar and involved with watershed quality issues value this move from the status quo \$66 more than those who are less aware. While preferences for the status quo may vary, the holistic set of preferences is consistent between rural and urban respondents in this watershed. ${ }^{12}$

\footnotetext{
${ }^{12}$ Regressions for the separate rural and urban subsamples can be found in Appendix C. A likelihood ratio test of joint preference stability tests the fit of separate regressions for the two subsamples against the constrained pooled sample. We fail to reject the null hypothesis that MWTP values are jointly similar across the two subsamples.
} 


\section{Integrated Assessment Application}

To illustrate how benefits from water quality improvements are distributed throughout the watershed, we recover the conditional individual-specific means of MWTP for every respondent in our sample (Greene, Hensher, and Rose 2005). We use the primary specification in our analysis (Table 2, column 1) to recover conditional individual-specific means. For each zip code in our sample, we average the MWTP over the respondents who lived in that zip code. This gives us zip code-level variation in the MWTP for each attribute.

Zip codes are considered rural if there are fewer than 1,000 residents per square mile, and urban otherwise (Ratcliffe et al. 2016; U.S. Census Bureau 2019). This allows us to tally welfare changes separately for the rural and urban areas in the USRW. The distributions of MWTP in the rural and urban zip codes are as expected and have significant overlap. ${ }^{13}$

Policy simulations, or "state-of-the-world" experiments, simulate a change in the levels of the environmental attributes to recover an individual's total WTP for the suite of improvements over the status quo level (Holmes, Adamowicz, and Carlsson 2017). For example, an individual's WTP for a change in attribute $x_{1}$ is that individual's MWTP for $x_{1}$ multiplied by the change in $x_{1}$ 's level: $W T P_{x_{1}}=M W T P_{x_{1}} \times \Delta x_{1}$. If more than one attribute is changing, then the individual's WTP for changes in both attributes is the sum of the WTP for each attribute $j$ that is changing:

$W T P=\sum_{j} M W T P_{x_{j}} \times \Delta x_{j}$.

Because we have zip code-specific MWTP for each attribute, we estimate changes in welfare for each zip code under different states of the world. Moreover, in zip code $z$ over $n$ households, the total WTP for improvements in a set of attributes indexed by $j$ is

\footnotetext{
${ }^{13} \mathrm{~A}$ full summary of the recovered conditional individual-specific means of the MWTP for each attribute can be found in Appendix D.
}

$$
W T P_{z}=\sum_{n} \sum_{j} M W T P_{z, x_{j}} \times \Delta x_{z, j} .
$$

From equation [5], the total WTP in the watershed is simply the sum of $W T P_{z}$ over all zip codes in the USRW.

Table 3 summarizes the results of our policy simulations. Panel A identifies the scenarios, panel B considers benefits from only the environmental attributes in the model, and panel $\mathrm{C}$ adds to panel $\mathrm{B}$ by also including the benefits from moving away from the status quo-the MWTP associated with the ASC in our model. The first scenario models a $50 \%$ reduction in only the frequency of algal blooms in river section A. Scenario 2 models this same improvement except for river section C. This allows us to hold all other attributes constant to see how benefits might accrue differently depending on where the improvement takes place. Scenario 3 models a $75 \%$ likelihood that the watershed reaches its nutrient loss target of $45 \%$ by the year 2040 . Scenario 4 introduces a more complete improvement scenario in which river section A sees a 75\% reduction in the frequency of algal blooms, sections A and $\mathrm{B}$ receive an additional 50 fish (population) per 100 yards of river, section A receives an additional two species of game fish per 100 yards of river, and there is a $100 \%$ likelihood of reaching the watershed's nutrient target.

Reducing the frequency of local algal blooms in just one of the four reaches of the watershed yields around $\$ 1$ million to $\$ 1.6$ million per year depending on the location of the improvement (Table 3, panel B, columns 1 and 2). A 75\% likelihood of reaching the nutrient target is worth $\$ 4.4$ million per year (Table 3, panel B, column 3). Finally, the most comprehensive scenario (Table 3, panel B, column 4) yields benefits of around \$7 million per year.

Table 3 also provides a summary of the average values per household for each of the scenarios. Household WTPs are calculated at the zip code level. We provide the average WTP for each scenario throughout the watershed as well as the average WTP in the rural and urban areas separately. Reducing algal blooms by $50 \%$ has an average value of $\$ 9$ or $\$ 15$ per year depending on where in the watershed it occurs, and the average value of a $75 \%$ 
Table 3

Sample Integrated Assessment Value Estimates (Total WTP)

\begin{tabular}{|c|c|c|c|c|}
\hline & (1) & (2) & (3) & (4) \\
\hline \multicolumn{5}{|l|}{ Panel A: Scenarios } \\
\hline Algal blooms & $\begin{array}{l}50 \% \text { reduced } \\
\text { Area A only }\end{array}$ & $\begin{array}{l}50 \% \text { reduced } \\
\text { Area C only }\end{array}$ & - & $\begin{array}{l}\text { 75\% reduced } \\
\text { Area A only }\end{array}$ \\
\hline Nutrient target & - & - & $75 \%$ likelihood & $100 \%$ likelihood \\
\hline Fish species & - & - & - & $\begin{array}{c}\text { +2 species } \\
\text { Area A only }\end{array}$ \\
\hline Fish population & - & - & - & $\begin{array}{l}+50 \text { population } \\
\text { Areas } \mathrm{A} \text { and } \mathrm{B}\end{array}$ \\
\hline \multicolumn{5}{|l|}{ Panel B: Without ASC } \\
\hline Total annual benefits (dollars) & $1,057,497$ & $1,697,818$ & $4,406,411$ & $7,126,757$ \\
\hline Rural areas & 768,279 & 985,443 & $2,612,890$ & $4,512,142$ \\
\hline Urban areas & 289,218 & 712,376 & $1,793,521$ & $2,614,615$ \\
\hline Mean benefits per household (dollars) & 9.30 & 14.93 & 38.75 & 62.67 \\
\hline Rural areas & 13.51 & 17.33 & 45.95 & 79.35 \\
\hline Urban areas & 5.09 & 12.53 & 31.54 & 45.98 \\
\hline \multicolumn{5}{|l|}{ Panel C: With ASC } \\
\hline Total annual benefits (dollars) & $3,648,648$ & $4,288,969$ & $6,997,562$ & $9,717,908$ \\
\hline Rural areas & $2,413,881$ & $2,631,044$ & $4,258,491$ & $6,157,744$ \\
\hline Urban areas & $1,234,768$ & $1,657,925$ & $2,739,071$ & $3,560,165$ \\
\hline Mean benefits per household (dollars) & 32.08 & 37.71 & 61.53 & 85.45 \\
\hline Rural areas & 42.45 & 46.27 & 74.89 & 108.3 \\
\hline Urban areas & 21.72 & 29.16 & 48.17 & 62.61 \\
\hline
\end{tabular}

Note: Benefits are estimated using equation [5]. These are estimates of compensating variation for the improvements modeled in the integrated assessment model exercise. In aggregate, rural areas of the watershed stand to benefit nearly twice as much as the urban clusters. Rural areas of the watershed also tend to have a higher per household WTP for each scenario. This is largely because a majority of the improvements will be realized in more rural areas of the watershed. ASC, alternative specific constant; WTP, willingness to pay.

change of the watershed doing its part for hypoxia reduction is $\$ 39$ per year per household. The comprehensive scenario in column 4 produces average benefits of $\$ 63$ per year per household.

To see where the benefits from the policy simulations accrue throughout the watershed, Figure 4 provides maps of both the total WTP (panel A) and the per household WTP (panel B) in each zip code. Benefits are most dense where population is most dense (panel A). However, when we map benefits based on per household estimates, we see the distribution is often higher in the rural areas throughout the watershed (panel B). ${ }^{14}$ Rural areas tend to

\footnotetext{
${ }^{14}$ Refinements could be made when modeling WTP throughout the watershed, or for use in transfer to similar watersheds, using spatial regression methods such as those discussed by Johnston, Besedin, and Holland (2019) or De Valk and Rolfe (2018). However, the focus of this paper is to provide a proof of concept for estimating the distributional
}

receive larger per household benefits because the river sections - and the corresponding improvements-are primarily in rural areas of the watershed.

\section{Discussion}

We have carried out a choice experiment survey to estimate how much residents in a subwatershed of the MRB are willing to pay to improve local fish diversity and populations in their rivers, reduce the prevalence of local algal blooms, and ensure that their watershed does its part to reduce hypoxia in the Gulf of Mexico. While current efforts in the MRB to reduce nutrients and sediment are driven by concern about water quality far away in the gulf, we find that people in our study area

effects of policies related to water quality that span geographically and culturally diverse landscapes. 


\section{Figure 4}

Spatial Distribution of Total Willingness to Pay in Each Zip Code throughout the Watershed (Panel A) and per Household Marginal Willingness to Pay (Panel B)
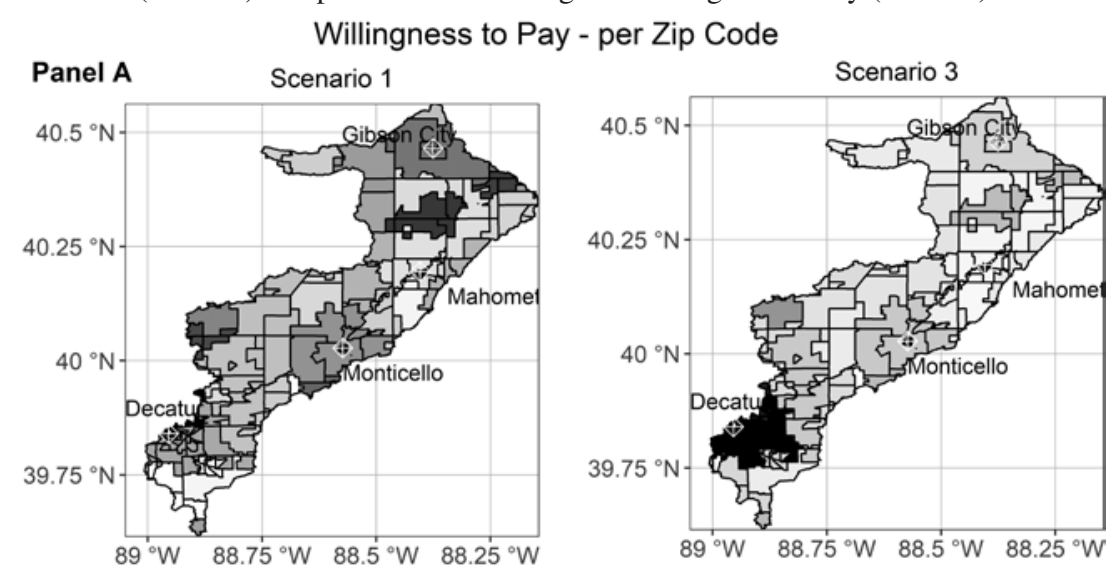

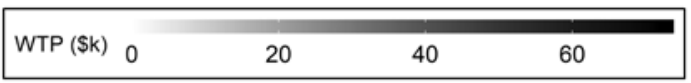
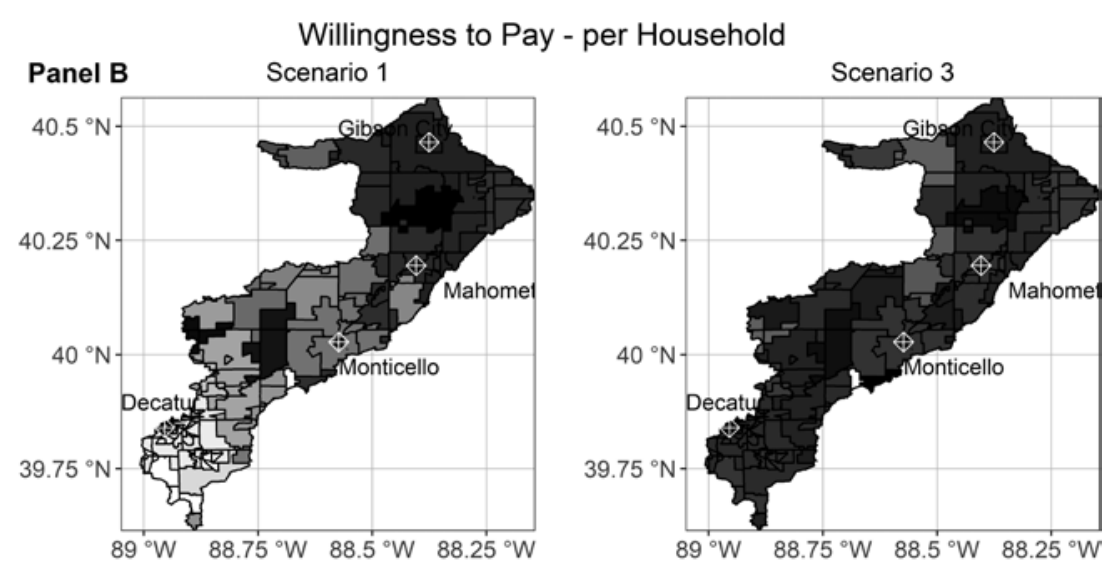

\begin{tabular}{|c|c|c|c|c|c|}
\hline WTP (\$ & 0 & 10 & 20 & 30 & 40 \\
\hline
\end{tabular}

would gain significant benefit from the local environmental improvements that could result from reduced nutrient pollution and from helping to reduce environmental problems in the gulf.

Much traditional research on surface water quality values has focused on generic measures of whether waters are boatable, fishable, and swimmable, and the resulting values can be quite small (Keiser, Kling, and Shapiro 2019). In contrast, we find that people would gain large value from reducing the frequency of local algal blooms, with respondents willing to pay nearly $\$ 40$ per year to reduce the frequency of nearby algal blooms by $50 \%$. Algal blooms are becoming more prevalent as climate change expands hot summer conditions; our result implies that economists and 
water quality modelers should pay increased attention to the impact of management and policies on those particularly harmful manifestations of nutrient pollution.

Residents of the U.S. Midwest gain no use value from reducing hypoxia in the Gulf of Mexico. However, we find that people in our study area would benefit from increasing the likelihood that their watershed reaches the target set for it under the INLRS; the average respondent would be willing to pay $\$ 48$ to have even a $50 \%$ chance of the watershed's goal being met. This finding provides further compelling rationale for investments in programs that would reduce nutrient loss, a discussion in which government agencies, NGOs, and industry groups are all currently engaged.

Our estimates suggest that people in this landlocked part of the Midwest would gain large value from improving local game fish diversity and fish populations. This result seems to be capturing significant nonuse values for having thriving river ecosystems in the region, since only a small fraction of respondents reported engaging in local fishing. Most previous research on the value of fish species and populations comes from travel cost and recreational site choice models that can only capture use values (Phaneuf et al. 2013; Melstrom et al. 2015). The large nonuse values we estimate in this study support the well-known claim that revealed preference estimates may not capture the full range of benefits from environmental improvements (Adamowicz et al. 1998; Hanley and Czajkowski 2019).

Economists, other social scientists, and policy makers have wondered if there is a rural-urban divide in the values people place on environmental improvements. In this case, we find that rural and urban preferences are similar. If anything, rural residents may place more value on a move away from the status quo toward environmental improvement. This finding implies that people in the rural areas, where many of the changes needed to improve water quality will be implemented, may also have high WTP for those improvements themselves.

Finally, the results from our simple simulations suggest that the total values water quality improvement could bring to a watershed like our study area are not trivial. For the USRW alone, total WTP for reaching a 75\% likelihood of reaching nutrient reduction targets (scenario 3) is estimated at approximately $\$ 4.4$ million annually. And when modeled with improvements that will likely come as complements for any policy targeting reductions in nutrient loss and transmission to the gulf (scenario 4), total annual benefits within this small watershed are estimated to exceed $\$ 7$ million per year.

Debate over nutrient loss reduction strategies continues. To inform that debate, analysts should quantify the full range of costs and benefits and how costs and benefits are distributed among groups of people in the landscape. Our findings can play an important role in that effort. However, more work needs to be done in order to further uncover and understand the overlooked benefits of reductions in nutrient loss and transmission. Future research would do well to explore how values vary throughout the MRB for improving local fish habitat, avoiding local algal blooms, and solving regional environmental problems like hypoxia in the Gulf of Mexico. Additional work is also needed to understand the factors driving people in our study to express such strong antipathy for a status quo that does nothing to address pervasive surface water pollution in the United States.

\section{Disclaimer and Acknowledgments}

The views expressed in this paper are those of the authors and do not necessarily reflect the views or policies of the U.S. Environmental Protection Agency. The paper has not been subjected to the agency's required peer and policy review. No official agency endorsement should be inferred. We would like to thank Maria Chu, Jason Knouft, and Alejandra Botero-Acosta for their work modeling the biophysical characteristics of the watershed, Ketong Xie for valuable research assistance, participants from the W4133 working group (2018) and the Program in Environmental and Resource Economics (pERE) at the University of Illinois Urbana-Champaign, Ben Gramig, Richard Ready, Klaus Moeltner, Robert Johnston, participants of the Social Cost of Water Pollution Working Group at Cornell University, and an anonymous 
reviewer for valuable feedback and suggestions made during the design, analysis, and submission stages of this study. This paper is based in part on work funded by USDA-NIFA grant \#1008843. All data and replication files can be found at https://doi.org/http://doi. org/10.5281/zenodo.3692738.

\section{References}

Adamowicz, Wiktor, Peter Boxall, Michael Williams, and Jordan Louviere. 1998. "Stated Preference Approaches for Measuring Passive Use Values: Choice Experiments and Contingent Valuation." American Journal of Agricultural Economics 80 (1): 64-75. https://doi. org/10.2307/3180269.

Adamowicz, Wiktor, Jordan Louviere, and Joffre Swait. 1998. Introduction to Attribute-Based Stated Choice Methods. Final report to Resource Evaluation Branch, Damage Assessment Center, NOAA. Washington, DC: National Oceanic and Atmospheric Administration.

Alexander, Richard B., Richard A. Smith, Gregory E. Schwarz, Elizabeth W. Boyer, Jacqueline V. Nolan, and John W. Brakebill. 2008. "Differences in Phosphorus and Nitrogen Delivery to the Gulf of Mexico from the Mississippi River Basin." Environmental Science and Technology 42 (3): 822-30. https://doi.org/10.1021/ es0716103

Andres, Kara J., Huicheng Chien, and Jason H. Knouft. 2019. "Hydrology Induces Intraspecific Variation in Freshwater Fish Morphology under Contemporary and Future Climate Scenarios." Science of the Total Environment 671: 421-30. https://doi.org/10.1016/j.scitotenv.2019.03.292.

Arcury, Thomas A., and Eric Howard Christianson. 1993. "Rural-Urban Differences in Environmental Knowledge and Actions." Journal of Environmental Education 25 (1): 19-25. https:// doi.org/10.1080/00958964.1993.9941940.

Babcock, Bruce A., and Catherine L. Kling. 2015. "Costs and Benefits of Fixing Gulf Hypoxia." Iowa Ag Review 14 (4): article 4. Available at https://lib.dr.iastate.edu/iowaagreview/vol14/ iss $4 / 4$.

Bergstrom, John C., and John B. Loomis. 2017. "Economic Valuation of River Restoration: An Analysis of the Valuation Literature and Its Uses in Decision-making." Water Resources and Economics 17: 9-19. https://doi.org/10.1016/j. wre.2016.12.001.
Botero-Acosta, A., M. L. Chu, and C. Huang. 2019. "Impacts of Environmental Stressors on Nonpoint Source Pollution in Intensively Managed Hydrologic Systems." Journal of Hydrology 579: 124056. https://doi.org/10.1016/j.jhydrol.2019.124056.

Brouwer, Roy, Julia Martin-Ortega, and Julio Berbel. 2010. "Spatial Preference Heterogeneity: A Choice Experiment." Land Economics 86 (3): 552-68. https://doi.org/10.3368/le.86.3.552.

Carson, Richard T., and Mikołaj Czajkowski. 2019. "A New Baseline Model for Estimating Willingness to Pay from Discrete Choice Models." Journal of Environmental Economics and Management 95: 57-61. https://doi.org/10.1016/j. jeem.2019.03.003.

Carson, Richard T., and Theodore Groves. 2007. "Incentive and Informational Properties of Preference Questions." Environmental and Resource Economics 37: 181-210. https://doi. org/10.1007/s10640-007-9124-5.

Carson, Richard T., and Robert Cameron Mitchell. 1993. "The Value of Clean Water: The Public's Willingness to Pay for Boatable, Fishable, and Swimmable Quality Water." Water Resources Research 29 (7): 2445-54. https://doi. org/10.1029/93WR00495.

Caussade, Sebastián, Juan Dios Ortúzar, Luis I. Rizzi, and David A. Hensher. 2005. "Assessing the Influence of Design Dimensions on Stated Choice Experiment Estimates." Transportation Research Part B: Methodological 39 (7): 62140. https://doi.org/10.1016/j.trb.2004.07.006.

Collins, Jill P., and Christian A. Vossler. 2009. "Incentive Compatibility Tests of Choice Experiment Value Elicitation Questions." Journal of Environmental Economics and Management 58 (2): 226-35. https://doi.org/10.1016/j. jeem.2009.04.004.

Coppess, Johnathan. 2016. "Dead Zones and Drinking Water, Part 3: The Illinois Nutrient Loss Reduction Strategy." Farmdoc Daily 6: 53. Available at https://farmdocdaily.illinois. edu/2016/03/dead-zones-drinking-water-part3. html.

Cummings, Ronald G., Glenn W. Harrison, and E. Elisabet Rutström. 1995. "Homegrown Values and Hypothetical Surveys: Is the Dichotomous Choice Approach Incentive-Compatible?" American Economic Review 85 (1): 260-66. https://www.jstor.org/stable/2118008.

Cummings, Ronald G., and Laura O. Taylor. 1999. "Unbiased Value Estimates for Environmental Goods: A Cheap Talk Design for the Contin- 
gent Valuation Method." American Economic Review 89 (3): 649-65. https://doi.org/10.1257/ aer.89.3.649.

Czajkowski, Mikołaj, Wiktor Budziński, Danny Campbell, Marek Giergiczny, and Nick Hanley. 2017. "Spatial Heterogeneity of Willingness to Pay for Forest Management." Environmental and Resource Economics 68: 705-27. https:// doi.org/10.1007/s10640-016-0044-0.

Czajkowski, Mikołaj, Nick Hanley, and Jacob LaRiviere. 2015. "The Effects of Experience on Preferences: Theory and Empirics for Environmental Public Goods." American Journal of Agricultural Economics 97 (1): 333-51. https:// doi.org/10.1093/ajae/aau087.

Czajkowski, Mikołaj, Christian A. Vossler, Wiktor Budziński, Aleksandra Wiśniewska, and Ewa Zawojska. 2017. "Addressing Empirical Challenges Related to the Incentive Compatibility of Stated Preferences Methods." Journal of Economic Behavior and Organization 142: 47-63. https://doi.org/10.1016/j.jebo.2017.07.023.

Daly, Andrew, Stephane Hess, and Kenneth Train. 2012. "Assuring Finite Moments for Willingness to Pay in Random Coefficient Models." Transportation 39: 19-31. https://doi. org/10.1007/s11116-011-9331-3.

De Valck, Jeremy, and John Rolfe. 2018. "Spatial Heterogeneity in Stated Preference Valuation: Status, Challenges and Road Ahead." International Review of Environmental and Resource Economics 11 (4): 355-422. https://doi. org/10.1561/101.00000097.

Diaz, Robert J., and Rutger Rosenberg. 2008. "Spreading Dead Zones and Consequences for Marine Ecosystems." Science 321 (5891): 92629. https://doi.org/10.1126/science.1156401.

Dissanayake, Sahan T. M., and Amy W. Ando. 2014. "Valuing Grassland Restoration: Proximity to Substitutes and Trade-offs among Conservation Attributes." Land Economics 90 (2): 237-59. https://doi.org/10.3368/le.90.2.237

Farber, Dan. 2018. "Politics, the Environment, and the Rural/Urban Divide." Legal Planet, October 29. Available at http://legal-planet. org/2018/10/29/environmental-law-and-the-rural-urban-divide.

Ferrini, Silvia, and Riccardo Scarpa. 2007. "Designs with A Priori Information for Nonmarket Valuation with Choice Experiments: A Monte Carlo Study." Journal of Environmental Economics and Management 53 (3): 342-63. https://doi.org/10.1016/j.jeem.2006.10.007.
Gibbs, Bob. 2016. "EPA Edicts Hurt Rural America." The Hill, February 8. https://thehill.com/ opinion/op-ed/268695-epa-edicts-hurt-ruralamerica.

Glenk, Klaus, Robert J. Johnston, Jürgen Meyerhoff, and Julian Sagebiel. 2019. "Spatial Dimensions of Stated Preference Valuation in Environmental and Resource Economics: Methods, Trends and Challenges." Environmental and Resource Economics 75: 215-42. https://doi.org/10.1007/s10640-018-00311-w.

Greene, William H., David A. Hensher, and John M. Rose. 2005. "Using Classical Simulation-Based Estimators to Estimate Individual WTP Values." In Applications of Simulation Methods in Environmental and Resource Economics, ed. Riccardo Scarpa and Anna Alberini, 17-33. Dordrecht: Springer Netherlands. https://doi.org/10.1007/1-4020-3684-1_2.

Greenley, Douglas A., Richard G. Walsh, and Robert A. Young. 1981. "Option Value: Empirical Evidence from a Case Study of Recreation and Water Quality." Quarterly Journal of Economics 96 (4): 657-73. https://doi. org/10.2307/1880746.

Hanley, Nick, and Mikołaj Czajkowski. 2019. "The Role of Stated Preference Valuation Methods in Understanding Choices and Informing Policy." Review of Environmental Economics and Policy 13 (2): 248-66. https://doi.org/10.1093/reep/ rez005.

Hanley, Nick, Felix Schläpfer, and James Spurgeon. 2003. "Aggregating the Benefits of Environmental Improvements: Distance-Decay Functions for Use and Non-use Values." Journal of Environmental Management 68 (3): 297-304. https://doi.org/10.1016/S03014797(03)00084-7.

Hanley, Nick, Robert E. Wright, and Vic Adamowicz. 1998. "Using Choice Experiments to Value the Environment." Environmental and Resource Economics 11: 413-28. https://doi. org/10.1023/A:1008287310583.

Hensher, David A., John M. Rose, and William H. Greene. 2005. Applied Choice Analysis: A Primer. Cambridge: Cambridge University Press.

Hess, Stephane, and Kenneth Train. 2017. "Correlation and Scale in Mixed Logit Models." Journal of Choice Modelling 23: 1-8. https:// doi.org/10.1016/j.jocm.2017.03.001.

Hole, Arne Risa. 2015. DCREATE: Stata Module to Create Efficient Designs for Discrete Choice Experiments. Statistical Software Components 
S458059. Boston: Boston College, Department of Economics.

Holmes, Thomas P., Wiktor L. Adamowicz, and Fredrik Carlsson. 2017. "Choice Experiments." In A Primer on Nonmarket Valuation, ed. Patricia A Champ, Kevin J. Boyle, and Thomas C. Brown, 133-86. Dordrecht: Springer.

Johnston, Robert J., Elena Y. Besedin, and Benedict M. Holland. 2019. "Modeling Distance Decay within Valuation Meta-analysis." Environmental and Resource Economics 72: 657-90. https://doi.org/10.1007/s10640-018-0218-z.

Johnston, Robert J., Elena Y. Besedin, and Ryan Stapler. 2017. "Enhanced Geospatial Validity for Meta-analysis and Environmental Benefit Transfer: An Application to Water Quality Improvements." Environmental and Resource Economics 68: 343-75. https://doi.org/10.1007/ s10640-016-0021-7.

Johnston, Robert J., Elena Y. Besedin, and Ryan F. Wardwell. 2003. "Modeling Relationships between Use and Nonuse Values for Surface Water Quality: A Meta-analysis." Water Resources Research 39 (12): 1363. https://doi. org/10.1029/2003WR002649.

Johnston, Robert J., Kevin J. Boyle, Wiktor (Vic) Adamowicz, Jeff Bennett, Roy Brouwer, Trudy Ann Cameron, W. Michael Hanemann, Nick Hanley, Mandy Ryan, Riccardo Scarpa, et al. 2017. "Contemporary Guidance for Stated Preference Studies." Journal of the Association of Environmental and Resource Economists 4 (2): 319-405. https://doi.org/10.1086/691697.

Johnston, Robert J., and Joshua M. Duke. 2007. "Is Willingness to Pay for Farmland Preservation Transferable across States? Evidence from a Choice Experiment." American Agricultural Economics Association (New Name 2008: Agricultural and Applied Economics Association). Milwaukee, WI: Agricultural and Applied Economics Association.

Johnston, Robert J., Benedict M. Holland, and Liuyang Yao. 2016. "Individualized Geocoding in Stated Preference Questionnaires: Implications for Survey Design and Welfare Estimation." Land Economics 92 (4): 737-759. https:// doi.org/10.3368/le.92.4.737.

Keiser, David A., Catherine L. Kling, and Joseph S. Shapiro. 2019. "The Low but Uncertain Measured Benefits of US Water Quality Policy." Proceedings of the National Academy of Sciences U S A 116 (12): 5262-69. https://doi. org/10.1073/pnas.1802870115.
Ladenburg, Jacob, and Søren Bøye Olsen. 2014. "Augmenting Short Cheap Talk Scripts with a Repeated Opt-Out Reminder in Choice Experiment Surveys." Resource and Energy Economics 37: 39-63. https://doi.org/10.1016/j.reseneeco.2014.05.002.

Lant, Cristopher L., and Rebecca S. Roberts. 1990. "Greenbelts in the Cornbelt: Riparian Wetlands, Intrinsic Values, and Market Failure." Environment and Planning A 22 (10): 1375-88. https:// doi.org/10.1068/a221375.

LaRiviere, Jacob, Mikołaj Czajkowski, Nick Hanley, Margrethe Aanesen, Jannike Falk-Petersen, and Dugald Tinch. 2014. "The Value of Familiarity: Effects of Knowledge and Objective Signals on Willingness to Pay for a Public Good." Journal of Environmental Economics and Management 68 (2): 376-89. https://doi. org/10.1016/j.jeem.2014.07.004.

Louviere, Jordan, Deborah Street, Richard Carson, Andrew Ainslie, J. R. Deshazo, Trudy Cameron, David Hensher, Robert Kohn, and Tony Marley. 2002. "Dissecting the Random Component of Utility." Marketing Letters 13: 177-93. https://doi.org/10.1023/A:1020258402210.

Manifold, Beverly. 1998. Executive Summary: The Quality of Our Nation's Water. Report to U.S. Congress. Washington, DC: U.S. Environmental Protection Agency.

McFadden, Daniel. 1973. "Conditional Logit Analysis of Qualitative Choice Behavior.” In Frontiers in Econometrics, ed. Paul Zarembka, 105-42. New York: Wiley.

Melstrom, Richard T., Frank Lupi, Peter C. Esselman, and R. Jan Stevenson. 2015. "Valuing Recreational Fishing Quality at Rivers and Streams." Water Resources Research 51 (1): 140-50. https://doi.org/10.1002/2014WR016152.

Meyerhoff, Jürgen, Marco Boeri, and Volkmar Hartje. 2014. "The Value of Water Quality Improvements in the Region Berlin-Brandenburg as a Function of Distance and State Residency." Water Resources and Economics 5: 49-66. https://doi.org/10.1016/j.wre.2014.02.001.

Mobley, Catherine. 2016. "What Matters When Explaining Environmentalism at the Watershed Level: Who You Are, Where You Live, What You See, or What You Perceive?" Environment and Behavior 48 (9): 1148-74. https://doi. org/10.1177/0013916515586058.

Moeltner, Klaus. 2019. "Bayesian Nonlinear Meta Regression for Benefit Transfer." Journal of Environmental Economics and Man- 
agement 93: 44-62. https://doi.org/10.1016/j. jeem.2018.10.008.

Needham, Katherine, and Nick Hanley. 2020. "Prior Knowledge, Familiarity and Stated Policy Consequentiality in Contingent Valuation." Journal of Environmental Economics and Policy 9 (1): 1-20. https://doi.org/10.1080/216065 44.2019.1611481.

Penn, Jerrod, and Wuyang Hu. 2020. "Certainty Follow-up Efficacy under Potential and Actual Hypothetical Bias: A Meta-analysis." American Journal of Agricultural Economics forthcoming.

Phaneuf, Daniel J. 2002. “A Random Utility Model for Total Maximum Daily Loads: Estimating the Benefits of Watershed-Based Ambient Water Quality Improvements." Water Resources Research 38 (11): 36-1-36-11. https://doi. org/10.1029/2001WR000959.

Phaneuf, Daniel J., Roger H. Haefen, Carol Mansfield, and George van Houtven. 2013. Measuring Nutrient Reduction Benefits for Policy Analysis Using Linked Non-market Valuation and Environmental Assessment Models. Final Report on Stated Preference Surveys. Report to the U.S. EPA. Washington, DC: U.S. Environmental Protection Agency.

Rabalais, N. N., R. J. Díaz, L. A. Levin, R. E. Turner, D. Gilbert, and J. Zhang. 2010. "Dynamics and Distribution of Natural and $\mathrm{Hu}-$ man-Caused Hypoxia." Biogeosciences 7: 585619. https://doi.org/10.5194/bg-7-585-2010.

Rabotyagov, Sergy S., Catherine L. Kling, Philip W. Gassman, Nancy N. Rabaliais, and R. Eugene Turner. 2014. "The Economics of Dead Zones: Causes, Impacts, Policy Challenges, and a Model of the Gulf of Mexico Hypoxic Zone." Review of Environmental Economics and Policy 8 (1): 58-79. https://doi.org/10.1093/reep/ ret024.

Racevskis, Laila A., and Frank Lupi. 2006. "Comparing Urban and Rural Perceptions of and Familiarity with the Management of Forest Ecosystems." Society and Natural Resources 19 (6): 479-95. https://doi. org/10.1080/08941920600663862.

Ratcliffe, Michael, Charlynn Burd, Kelly Holder, and Alison Fields. 2016. Defining Rural at the U.S. Census Bureau. Washington, DC: U.S. Census Bureau. Available at https://www2.census.gov/geo/pdfs/reference/ua/Defining_Rural. pdf.

Ready, Richard C., Patricia A. Champ, and Jennifer L. Lawton. 2010. "Using Respondent Uncer- tainty to Mitigate Hypothetical Bias in a Stated Choice Experiment." Land Economics 86 (2): 363-81. https://doi.org/10.3368/le.86.2.363.

Salka, William M. 2001. "Urban-Rural Conflict over Environmental Policy in the Western United States." American Review of Public Administration 31 (1): 33-48. https://doi. org/10.1177/02750740122064820.

Sarrias, Mauricio, and Ricardo Daziano. 2017. "Multinomial Logit Models with Continuous and Discrete Individual Heterogeneity in R: The gmnl Package." Journal of Statistical Software 79 (2): 1-46. https://doi.org/10.18637/jss. v079.i02.

Scarpa, Riccardo, Mara Thiene, and Kenneth Train. 2008. "Utility in Willingness to Pay Space: A Tool to Address Confounding Random Scale Effects in Destination Choice to the Alps." American Journal of Agricultural Economics 90 (4): 994-1010. https://doi.org/10.1111/ j.1467-8276.2008.01155.x.

Schaafsma, Marije, and Roy Brouwer. 2013. "Testing Geographical Framing and Substitution Effects in Spatial Choice Experiments." Journal of Choice Modelling 8: 32-48. https://doi. org/10.1016/j.jocm.2013.04.007.

Street, Deborah J., and Leonie Burgess. 2007. The Construction of Optimal Stated Choice Experiments: Theory and Methods. Hoboken, NJ: John Wiley and Sons.

Sutherland, Ronald J., and Richard G. Walsh. 1985. "Effect of Distance on the Preservation Value of Water Quality." Land Economics 61 (3): 281-91. https://doi.org/10.2307/3145843.

Swait, Joffre, and Wiktor Adamowicz. 2001. "Choice Environment, Market Complexity, and Consumer Behavior: A Theoretical and Empirical Approach for Incorporating Decision Complexity into Models of Consumer Choice." Organizational Behavior and Human Decision Processes 86 (2): 141-67. https://doi. org/10.1006/obhd.2000.2941.

Swait, Joffre, and Jordan Louviere. 1993. "The Role of the Scale Parameter in the Estimation and Comparison of Multinomial Logit Models." Journal of Marketing Research 30 (3): 305-14. https://doi.org/10.1177/002224379303000303.

Thiene, Mara, and Riccardo Scarpa. 2009. "Deriving and Testing Efficient Estimates of WTP Distributions in Destination Choice Models." Environmental and Resource Economics 44: article 379. https://doi.org/10.1007/s10640-0099291-7. 
Train, Kenneth. 1998. "Recreation Demand Models with Taste Differences over People." Land Economics 74 (2): 230. https://doi. org/10.2307/3147053.

Train, Kenneth, and Melvyn Weeks. 2005. "Discrete Choice Models in Preference Space and Willingness-to-Pay Space." In Applications of Simulation Methods in Environmental and Resource Economics, ed. Riccardo Scarpa and Anna Alberini, 1-16. Dordrecht: Springer Netherlands. https://doi.org/10.1007/1-40203684-1_1.

U.S. Census Bureau. 2019. 2013-2017 American Community Survey (ACS) 5-Year Estimates. Washington, DC: U.S. Census Bureau.

U.S. Environmental Protection Agency. 2008. Mississippi River/Gulf of Mexico Watershed Nutrient Task Force. Gulf Hypoxia Action Plan 2008 for Reducing, Mitigating, and Controlling Hypoxia in the Northern Gulf of Mexico and Improving Water Quality in the Mississippi River
Basin. Washington, DC: U.S. Environmental Protection Agency.

. 2013. Hypoxia Task Force Reassessment 2013: Assessing Progress Made Since 2008. Washington, DC: U.S. Environmental Protection Agency.

Van Houtven, George, John Powers, and Subhrendu K. Pattanayak. 2007. "Valuing Water Quality Improvements in the United States Using Meta-analysis: Is the Glass Half-Full or HalfEmpty for National Policy Analysis?" Resource and Energy Economics 29 (3): 206-28. https:// doi.org/10.1016/j.reseneeco.2007.01.002.

Whitehead, John C., Glenn C. Blomquist, Thomas J. Hoban, and William B. Clifford. 1995. "Assessing the Validity and Reliability of Contingent Values: A Comparison of On-Site Users, Off-Site Users, and Non-users." Journal of Environmental Economics and Management 29 (2): 238-51. https://doi.org/10.1006/ jeem.1995.1044. 